Gustavo Henrique Vieira de Castro ${ }^{1}$

Meg Sarkis Simão Rosa ${ }^{2}$

Rogério Ramos Marques ${ }^{3}$
* Recebido em: 15/05/2012

Aprovado em: 02/03/2013

1 Contador (Centro Universitário de Brasília - UniCEUB) e analista do Banco Regional de Brasília.

2 Contadora (Centro Universitário de Brasília UniCEUB), especialista em auditoria (Universidade de Brasília - UnB) e em Contabilidade e Finanças (Universidade Federal do Paraná UFP). Mestre em Ciências Contábeis (UnB).

3 Contador (UnB), especialista em perícia contábil (União Educacional de Brasília - Uneb), administração financeira (Fundação Getúlio Vargas - FGV) e controladoria (UnB) e mestre em Ciências Contábeis (UnB). Atua como professor, coordenador do Curso de Ciências Contábeis do UniCEUB e Auditor Interno.

\section{O efeito da crise de 2008 na saúde econômica financeira dos bancos no Brasil: uma análise comparativa entre instituições públicas e privadas no período de 2007 a $2010^{*}$}

\section{The economic and financial impacts of the $\mathbf{2 0 0 8}$ crisis in Brazilian banks: a comparative analysis between public and private institutions from 2007 to 2010}

\section{Resumo}

O objetivo deste artigo reside em verificar o impacto da crise de 2008 na saúde econômico-financeira dos bancos públicos e privados que atuam na economia brasileira, no sentido de responder à seguinte questão: houve piora da saúde econômico-financeira das instituições financeiras públicas em relação às privadas, em função das medidas anticíclicas adotadas para conter a crise de 2008? Para atingir esse objetivo, foram selecionados demonstrativos contábeis (balanço patrimonial e demonstração de resultados), referentes aos exercícios sociais de 2007, 2008, 2009 e 2010, dos principais bancos que operam no Brasil. Essas demonstrações foram analisadas por meio de indicadores calculados a partir das informações contábeis. O resultado da pesquisa apontou que a ação anticíclica de bancos públicos, por meio da ampliação do crédito em momentos de intensa preferência pela liquidez e contração de empréstimos por parte dos bancos privados, na busca de incentivar vários setores da economia e contribuir com menor intensidade da crise, foi acompanhado por um desempenho inferior aos dos bancos privados, conforme os indicadores calculados.

Palavras-chave: Crise 2008. Instituições financeiras. Análise econômicofinanceira. Demonstrações contábeis.

\begin{abstract}
This article aims to verify the impact of the 2008 crisis in the economic and financial health of Brazilian public and private banks, in order to answer the following question: did the economic-financial health of public financial institutions get worst in relation to the private banks, considering the countercyclical efforts used to contain the 2008 crisis? To achieve this goal there were selected accounting balance sheets of 2007, 2008, 2009 and 2010 regarding the Brazilian most important banks. These documents were analysed using indicators which were calculated from the accounting information. The research result reveals that the countercyclical action of the public banks, by credit offering extension at economic moments of intense liquidity pre-
\end{abstract}


ference, and the loans taken by the private banks, in order to incentivize economic sectors and to contribute to lower the crisis intensity, were followed by a low degree performance of private banks, according to the research indicators.

Keywords: Crisis in 2008. Financial institutions. Financial analysis. Financial statements.

\section{Introdução}

Nos últimos anos, discussões sobre instabilidade financeira dos mercados e o efeito nas empresas têm sido recorrentes no meio empresarial e na academia. Uma das últimas crises econômicas com efeito mundial, por exemplo, foi à crise do subprime nos Estados Unidos em 2008. Em termos de gravidade dos problemas decorrentes, essa crise pode ser comparada à crise de 1929 (PEREIRA, 2009). Apesar de sua gravidade:

[...] sua repercussão sobre a economia brasileira, ainda que relevante, foi relativamente limitada, se comparada com o que ocorreu em diversas outras, tanto do ponto de vista da duração da recessão quanto de seu impacto sobre o sistema financeiro e o mercado de trabalho. Isso refletiu condições iniciais mais favoráveis, bem como a política de gestão de crise adotada (MESQUITA; TORÓS, 2010, 189).

O sistema financeiro é altamente sensível aos efeitos sistêmicos das crises econômicas. A falência do Lehman Brothers, banco de 158 anos de idade, respeitado pelos negócios e o quarto maior dos Estados Unidos, [...] marcou o início do período de agravamento da crise financeira que abalou o mundo e levou as principais economias a um período de forte recessão" (SÍMBOLO, 2009).

Os efeitos da crise repercutiram mais intensamente na economia brasileira a partir de setembro de 2008, principalmente sob o aspecto da paralisação do mercado de crédito, cujo processo de crescimento voltou a ocorrerem 2009 em função de medidas adotadas pelo governo federal com o objetivo de mitigar os seus efeitos (BANCO CENTRAL DO BRASIL, 2009).

No âmbito do Banco Central do Brasil, diversas medidas foram tomadas com o objetivo de evitar maior impacto da crise de 2008 no Sistema Financeiro Brasileiro, tais como: alteração nos recolhimentos compulsórios, flexibilização dos direcionamentos obrigatórios do crédito, aperfeiçoamento do Sistema Brasileiro de Pagamentos
(SBP), modificações nas regras de classificação das operações de crédito e de constituição de provisões, maior exigência na transparência das operações bancárias, exigência sobre o custo efetivo total das operações com os clientes dos bancos, ampliação da base de cobertura da Central de Riscos do Bacen com maior divulgação de informações sobre o papel dessa Central, de portabilidade de informações cadastrais e de operações de crédito, entre outras.

Carneiro et al (2009 apud LODI, 2010) destacam que os bancos públicos tiveram um papel decisivo na atenuação do efeito-contábil da crise de 2008 sobre o Sistema Financeiro Nacional. A ação anticíclica dessas instituições por meio da ampliação do crédito em momentos de intensa preferência pela liquidez e contração de empréstimos por parte dos bancos privados buscaram incentivar vários setores da economia como a indústria, $\mathrm{o}$ comércio e a construção civil. Essas ações influenciaram na menor intensidade da crise e por um período mais curto do seu efeito.

Nesse contexto, a presente pesquisa propõe-se a verificar o impacto da crise de 2008 na saúde econômicofinanceira das instituições financeiras públicas e privadas que atuam na economia brasileira, no sentido de responder à seguinte questão: houve piora da saúde econômico-financeira das instituições financeiras públicas, em relação às privadas, em função das medidas anticíclicas adotadas para conter a crise de 2008 ?

Para atingir o objetivo geral, foram estabelecidos os seguintes objetivos específicos:

a) selecionar demonstrativos contábeis (balanço patrimonial e demonstração de resultados), referentes aos exercícios sociais de 2007, 2008, 2009 e 2010 dos principais bancos que operam no Brasil. O período dos demonstrativos estabelecido tem como objetivo analisar a situação econômico-financeira antes e depois do início (2008)da crise;

b) estabelecer os indicadores econômico-financeiros a partir das demonstrações contábeis dos bancos selecionados; e

c) analisar os bancos a partir dos indicadores calculados. 
O presente artigo não tem a pretensão de esgotar o assunto sobre a saúde econômico-financeira dos bancos e nem avaliar as medidas interpostas pelo governo, via instituições federais. A principal questão é observar se houve efeito diferenciado em bancos públicos comparativamente aos privados.

\section{A crise financeira de 2008}

A crise de 2008 apenas encontra paralelo com a crise de 1929, a que gerou o crash de Wall Street e, apesar de todas essas semelhanças, o impacto sobre a economia brasileira foi relevante, porém não tão representativo como em outras economias, tanto do ponto de vista de duração quanto no de impacto (MESQUITA; TORÓS, 2010).

A falência do banco de investimento Lehman Brothers, em 15 de setembro de 2008, marcou a transformação da crise financeira internacional, iniciada no mercado americano de hipotecas de alto risco em meados de2007, em uma crise global sistêmica (FREITAS, 2009). As condições oferecidas pelo mercado de muito otimismo, de alta liquidez e de economia aquecida levaram as instituições bancárias e as não bancárias a operarem com maior tolerância ao risco para obtenção de maiores retornos, o que as levou a participações vultosas no mercado hipotecário americano, incluindo segmentos com fundamentação de crédito mais frágil, os chamados subprimes (BADARÓ, 2007).

A crise de 2008começou, na verdade, há vários anos antes. O mercado imobiliário começou a crescer a partir do biênio 2000/2001 em função da crise no mercado de ações norte-americano. Aproveitando a valorização imobiliária, as famílias estadunidenses, já apresentando algum grau de endividamento, elevaram ainda mais suas dívidas fazendo novas hipotecas e contraindo mais empréstimos. Com a alta valorização dos imóveis, as condições de crédito foram facilitadas para as famílias e indivíduos sem histórico de crédito ou com histórico ruim, sem emprego e sem renda. São os chamados subprime. Para diluir o risco dessas operações mais arriscadas, os bancos norte-americanos credores emitiram títulos negociáveis (derivativos) no mercado financeiro internacional, “[...] cujo valor era cinco vezes superior ao das dívidas originais". A euforia começou a acabar quando os juros aumentaram nos Estados Unidos com consequente queda do preço dos imóveis. Isso acarretou inadimplência em massa, repercutindo na situação de insolvência dos bancos e consequentemente, na queda das bolsas de valores de todo o mundo. O efeito sistêmico da quebra ocorreu em função da venda e da compra, em enormes quantidades, dos títulos lastreados em hipotecas subprime, provocando o alastramento da crise, de origem estadunidense, para os principais bancos do mundo.

O efeito contágio da crise econômica mundial atingiu o Brasil em setembro de 2008 quando o mercado de crédito vivenciava a fase ascendente de um ciclo de crédito extremamente favorável e longo, sob a liderança de bancos privados. Isso foi proporcionado pela progressiva melhora do ambiente macroeconômico, o qual induziu os bancos à redefinição de suas estratégias operacionais com prioridade para a expansão do crédito às pessoas físicas (PRATES; BANCARELI, 2009 apud LODI, 2010).

O Banco Central adotou uma série de medidas para o enfrentamento da crise e, segundo Mesquita e Torós (2010), houve a preocupação de que as medidas adotadas não comprometessem o regime de política monetária voltada para promover a convergência da inflação à trajetória de metas e à flutuação cambial. De acordo com o Relatório de Economia Bancária e Crédito 2009, foram adotadas as seguintes medidas:

a) alteração dos recolhimentos compulsórios: utilizado como instrumentos de política monetária, a diminuição dos depósitos compulsórios objetivou contribuir para o aumento da oferta de crédito e a redução do spread bancário;

b) aplicações diretas e indiretas dos recolhimentos compulsórios em créditos: foi autorizada a utilização de até $40 \%$ dos recolhimentos compulsórios sobre recursos a prazo para aquisição interbancária de operações de crédito, dentre outras medidas, objetivando a manutenção da liquidez e do crédito concedido pelas pequenas e médias instituições;

c) operações especiais do Banco Central para resguardar a liquidez do Sistema Financeiro Nacional (SFN) e das operações internacionais do país: autorização para o Conselho Monetário Nacional (CMN), por meio da Medida Provisória (MP) n ${ }^{\circ}$ 
442, de 6/10/2008, estabelecer critérios de avaliação de ativos recebidos pelo Banco Central do Brasil (BCB) em operações de redesconto em moeda nacional ou em garantia de empréstimos em moeda estrangeira. O objetivo era regularizar a liquidez e compensar a escassez de linhas de crédito internacional causada pela crise;

a) aperfeiçoamento do Sistema de Pagamentos Brasileiro (SPB);

b) modificações nas regras de classificação das operações de crédito e de constituição de provisões para aumentar a segurança das operações de crédito, disseminando melhor a cultura de crédito no país;

c) transparência nas operações bancárias com relação às informações detalhadas sobre juros e sobre encargos das principais operações de crédito e divulgação à população pela internet;

d) informação do Custo Efetivo Total (CET) das operações a realizar com os clientes;

e) Central de Risco (atual Sistema de Informações de Crédito - SCR) do Bacen: medidas para reduzir o limite de valor informado e melhoria da qualidade da informação disponibilizada;

f) portabilidade de informações cadastrais e de operações de crédito;

g) elaboração de cartilha sobre portabilidade de informações cadastrais;

h) promoção de mais concorrência no cheque especial;

i) redução de exigências burocráticas com relação a operações de pequeno valor;

j) securitização e negociação de recebíveis para estimular a disseminação e o crescimento desse mercado;

k) derivativos de crédito como uma forma de possibilitar o uso desses instrumentos de redução e a transferência dos riscos de crédito.
Carneiro et al (2009 apud LODI, 2010) destacam que a desaceleração do crédito em 2008 somente não foi mais intensa devido à ação anticíclica dos bancos públicos, onde:

[...] nesse contexto de forte aversão ao risco por parte dos bancos privados, tanto o $\mathrm{BB}$, como a $\mathrm{CEF}$, aliando as diretrizes governamentais com suas próprias estratégias operacionais, ampliaram os empréstimos à indústria, aos setores terciários e à infraestrutura, inclusive a partir de recursos livres (ou de tesouraria), exercendo um importante papel anticíclico, ao lado do BNDES. Ademais, as duas primeiras instituições também seguiram a orientação do governo de baixar as taxas de juros do crédito de forma a pressionar os bancos privados a reduzirem seus elevados spreads, como já mencionado. Vale destacar que, no caso do BB, o governo utilizou a prerrogativa de acionista majoritário e determinou a troca do seu presidente, o que garantiu o desempenho das funções de banco público no momento de crise. No caso da CEF, a crise revelou-se uma janela de oportunidade no sentido de ampliar suas fatias nos demais segmentos do mercado de crédito corporativo, além do imobiliário.

\section{A análise das demonstrações contábeis}

Para verificar a situação econômico-financeira dos bancos no período de 2007 a 2010, faz-se necessário o uso de técnicas de análise de demonstrações contábeis.

De acordo com o Comitê de Pronunciamentos Contábeis, com relação ao Pronunciamento Conceitual Básico (R1) - Estrutura Conceitual para Elaboração e Divulgação de Relatório Contábil-Financeiro (2011):

[...] as demonstrações contábeis são elaboradas e apresentadas para usuários externos em geral, tendo em vista suas finalidades distintas e necessidades diversas. Governos, órgãos reguladores ou autoridades tributárias, por exemplo, podem determinar especificamente exigências para atender a seus próprios interesses. Essas exigências, no entanto, não devem afetar as demonstrações contábeis elaboradas segundo esta Estrutura Conceitual. Demonstrações contábeis elaboradas dentro do que prescreve esta Estrutura Conceitual objetivam fornecer informações que sejam úteis na tomada de decisões econômicas e avaliações por parte dos usuários em geral, não tendo o propósito de atender finalidade ou necessidade específica de determinados grupos de usuários.

Por meio das demonstrações contábeis elaboradas por uma empresa, é possível extrair informações a respeito de sua posição econômica e financeira atual, as causas 
que determinaram a evolução apresentada e as tendências futuras (ASSAF NETO, 2012a).

Penman $(2013,195$.$) aborda aspectos sobre as de-$ monstrações contábeis e afirma que esses relatórios:

[...] são uma lente aplicada a um negócio e desenham um quadro que entra em foco com a análise da demonstração financeira, e o analista deve entender como o quadro é desenhado e como a análise pode deixá-lo mais nítido. Dois aspectos das demonstrações precisam ser apreciados: forma e conteúdo. O primeiro descreve como elas são organizadas. A análise da demonstração financeira é um modo organizado de extrair informações nelas contidas, mas para organizá-la, em primeiro lugar, temos de entender como elas são organizadas. [...] Já o segundo preenche a forma e colore o esboço, descrevendo como são medidos os itens de linha ditados pela forma, como lucros, ativos e passivos, quantificando a mensagem.

A análise das demonstrações financeiras tem como objetivo o estudo do desempenho econômico-financeiro de uma empresa, considerando um determinado período de tempo passado para, a partir daí, diagnosticar sua posição atual e produzir resultados que sirvam de base para a previsão de tendências futuras. Na realidade, o que se pretende avaliar são os reflexos que as decisões tomadas por uma empresa determinam sobre sua liquidez, estrutura patrimonial, rentabilidade etc. (ASSAF NETO, 2012b).

Uma técnica bastante utilizada para analisar demonstrações contábeis é realizada por meio de índices, que são:

[...] a relação entre contas ou grupo de contas das demonstrações financeiras, que visa evidenciar determinado aspecto da situação econômica ou financeira de uma empresa. [...]Assim como um médico usa certos indicadores, como pressão, temperatura, para elaborar o quadro clínico do paciente, os índices financeiros permitem construir um quadro de avaliação da empresa (MATARAZZO, 2010, 147).

Os índices utilizados na pesquisa são os considerados por Assaf Neto (2012a) para a análise de instituições financeiras, quais sejam:

a) Custo Médio de Captação: relação entre as despesas de captação no mercado apropriadas em cada exercício e o total dos depósitos a prazo mantidos pelo banco. Revela o custo financeiro do capital investido na instituição por poupadores (custo de captação). b) Retorno Médio das Operações de Crédito: relação entre as receitas financeiras provenientes das operações de crédito e o valor médio aplicado em créditos. Apura a taxa de retorno das aplicações em créditos, a qual é geralmente confrontada com o custo de captação para se avaliar o spread bruto do banco.

c) Lucratividade dos Ativos: relação entre as receitas de intermediação financeira e o ativo total do banco. É a porcentagem do total investido na instituição (ativo total) que se transformou em receitas financeiras.

d) Índice de Eficiência: relação entre as despesas operacionais incorridas no exercício e as receitas de intermediação financeira. Pode revelar a produtividade do banco.

e) Leverage: relação entre o ativo total e o patrimônio líquido. Revela quantas vezes o ativo do banco é maior que o capital próprio investido.

f) Retorno Médio sobre o Patrimônio Líquido (ROE):relação entre o resultado líquido e o patrimônio líquido médio do exercício. É a taxa de retorno do capital próprio.

g) Participação dos Empréstimos: relação entre as operações de crédito e o ativo total. Percentual do ativo total de um banco que se encontra aplicado em operações de empréstimos (créditos).

\section{Metodologia}

Neste trabalho, as técnicas utilizadas são a pesquisa bibliográfica, por meio de consulta a livros, a artigos, a revistas, a demonstrações contábeis de bancos e a outros documentos, objetivando a fundamentação teórica da pesquisa com relação aos aspectos relacionados à crise financeira de 2008 e ao reflexo nas demonstrações contábeis dos bancos que operam na economia brasileira. Trata-se, portanto, de uma pesquisa documental. Segundo 
Martins e Theóphilo (2009), a pesquisa documental é caracterizada por estudos que utilizam documentos como fontes de dados, de informações e de evidências.

Foram considerados os demonstrativos financeiros consolidados dos quatro maiores bancos, em termos de ativo total, que operam no Brasil: Banco do Brasil S/A; Banco Bradesco S/A; Itaú Unibanco Holding S/A e Banco Santander (Brasil) S/A. A Caixa Econômica Federal, embora seja a $4^{\text {a }}$ maior instituição financeira no Brasil em ativos, segundo o Bacen, foi excluída da análise tendo em vista suas características diferenciadas em termos de tipo societário (empresa pública) de atuação no mercado de capitais.

Para verificar o impacto da crise, optou-se por considerar o ano de 2007, o ano do auge da crise (2008) e o biênio posterior para verificar o efeito das medidas anticíclicas. Os demonstrativos foram obtidos por meio de consulta à própria página eletrônica das instituições. Para realizar a comparação dos períodos, os demonstrativos foram corrigidos monetariamente pelo Índice Nacional de Preços ao Consumidor Amplo - IPCA, calculado pelo Instituto Brasileiro de Geografia e Estatística - IBGE para dezembro de 2010.

As instituições financeiras selecionadas foram escolhidas com base em sua representatividade no mercado financeiro. Apesar de ser uma amostra pequena em relação ao número de instituições, ela se torna representativa ao considerar que os bancos, a saber, Banco do Brasil, Santander, Itaú e Bradesco representam juntos $66,51 \%$ do Sistema Financeiro Nacional, tomando como base o ativo total dessas instituições financeiras.

O Banco do Brasil, apesar de ser um instrumento utilizado pelo governo federal para promover o desenvolvimento sustentável, é uma empresa de economia mista, com ações negociadas na Bolsa de Valores, Mercadorias e Futuros de São Paulo - BM\&FBOVESPA. As decisões estratégicas são tomadas considerando-se a preocupação com o retorno dos acionistas. É o maior banco do país, em ativos totais, e com participação significativa no mercado de crédito brasileiro.

O Itaú Unibanco Holding S/A foi cotado no ano de 2010 como uma das 10 maiores instituições financeiras do mundo, pela agência internacional de notícias Bloomberg. Além disso, o Itaú Unibanco também é tido como uma referência quando o foco é sustentabilidade e desempenho, tendo ganhado vários prêmios nacionais e internacionais. No Brasil, conforme dados do Bacen, é o segundo maior banco em ativos totais.

O Bradesco é o terceiro maior banco do Brasil e possui a maior rede de agências no setor privado brasileiro. Tem uma participação significativa em operações de crédito, seguros e capitalizações. Recebeu da Standard e Poor's Governance Services - agência americana que fornece informações ao mercado para facilitar a tomada de decisões em investimentos, na forma de índices, pesquisas, ratings de crédito, etc. - o Escore Gamma7, que é o maior já concedido mundialmente em termos de Governança Corporativa.

O Santander (Brasil) é, atualmente, o $5^{\circ}$ maior banco brasileiro em total de ativo e o $4^{\circ}$ maior banco mundial (considerando o grupo Santander). Após a aquisição do Banco Real, que naquele momento era o $4^{\circ}$ maior banco brasileiro em volume de ativos, passou a postular entre os grandes bancos brasileiros e tem a maior parte de suas operações voltadas para as regiões Sul e Sudeste, regiões que apresentam, aproximadamente, $73 \%$ do PIB brasileiro.

Para avaliar a evolução da situação econômicofinanceira dos bancos no período mencionado, fora utilizados os seguintes indicadores:

a) Custo Médio de Captação:

DespesasFinanceirasd eCaptaçãonoMercado DepósitosaPrazo

b) Retorno Médio das Operações de Crédito: $\frac{\text { Receitas Financeiras de Operações de Crédito }}{\text { Operações de Crédito }}$

c) Lucratividade dos Ativos:

d) Receitas de Interme diação Financeina Ativos

e) Índice de Eficiência:

Despasas operacionais Receitas de Intermediação Financeira

f) Leverage:

$\frac{\text { Ativo }}{\text { Patrimônio Liquido }}$

g) Retorno Médio sobre o Patrimônio Líquido (ROE): 


\section{Lucro Líquido \\ Patrimônio Liquido}

h) Participação dos Empréstimos:

Operações de Crédito

Ativo

\section{Resultados da pesquisa}

Os resultados apurados indicam que o custo médio de captação (Gráfico 1) das instituições teve um decréscimo em 2008. Porém, logo após o aumento da taxa Selic, o custo médio de captação dos bancos teve um comportamento semelhante, exceto o Itaú, cujo índice ajustou-se ao dos outros bancos somente em 2010. Isso ocorreu provavelmente em função da fusão dessa instituição com o Unibanco em 2008.

Gráfico 1 - Custo médio de captação.

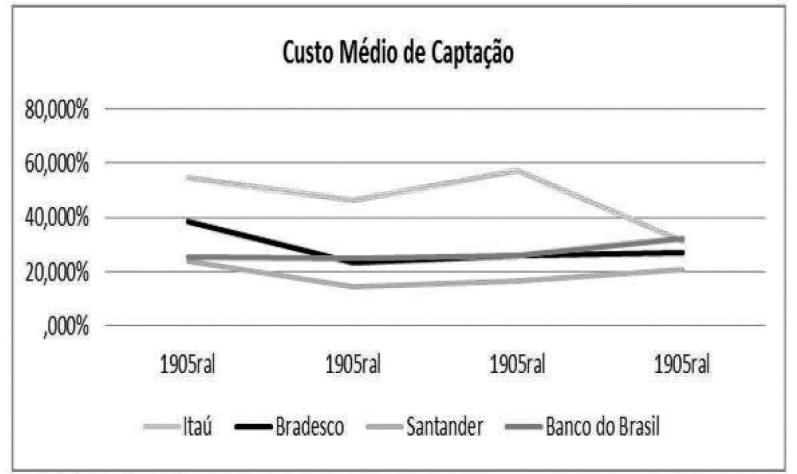

Fonte: elaborado pelo autor

A análise do retorno sobre operações de crédito dos bancos no período 2007 a 2010 revela que as empresas privadas mantiveram esse indicador em nível superior ao do Banco do Brasil, praticamente em todo o período sob análise. Esse comparativo evidencia a liderança do BB no processo de redução de custo das operações de crédito para os clientes, como medidas anticíclicas da crise, razão pela qual o seu retorno foi inferior.

A instituição financeira que se destacou das demais foi o Itaú Unibanco, sempre permanecendo com o índice superior. As outras instituições financeiras analisadas não apresentaram variações significativas entre si, porém, é importante ressaltar o movimento contrário do Bradesco em relação às outras três instituições, ao obter alta em 2008, baixa em 2009 e novamente alta em 2010. Esse movimento contrário do Bradesco se deve à carac- terística da empresa na "democratização" do crédito, não estando avesso ao risco da classe baixa e média, fazendo destes o maior volume de operações da instituição.

Gráfico 2 - Retorno sobre operações de crédito.

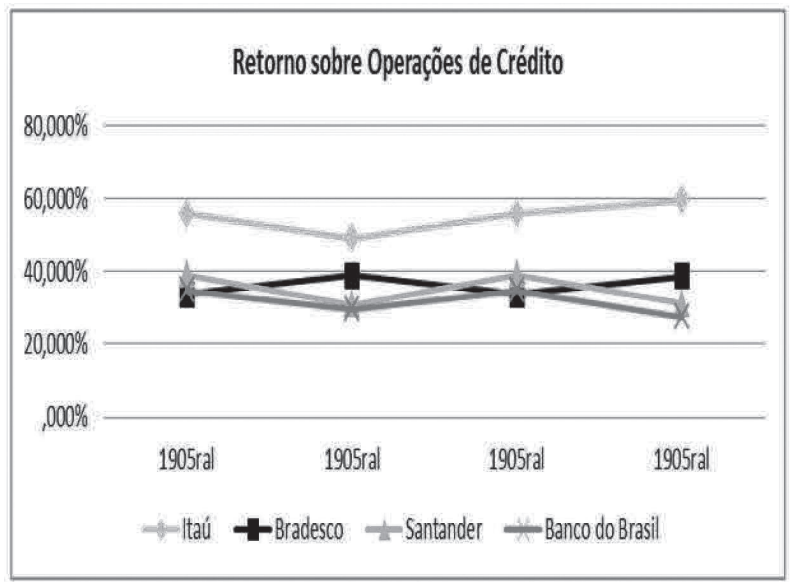

Fonte: elaborado pelo autor

A lucratividade dos ativos revela que houve uma queda no ano da crise financeira de 2008, com exceção do Banco do Brasilque apresentou crescimento, e uma tendência de estabilidade no biênio 2009/2010. O Santander apresentou comportamento da lucratividade em níveis inferiores ao índice dos outros bancos, mas com tendência de chegar ao nível das demais instituições, objetos de análise em 2010.

Gráfico 3 - Lucratividade dos ativos.

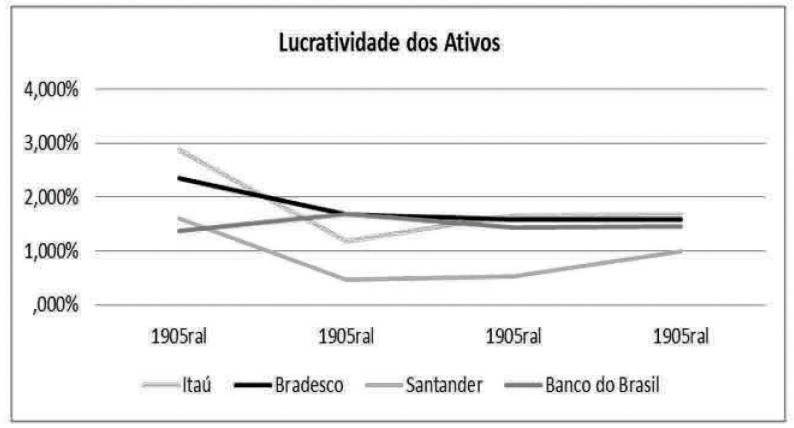

Fonte: elaborado pelo autor

O índice de eficiência relaciona as despesas operacionais da instituição com sua receita de intermediação financeira. Se esse índice apresentar-se em 100\%, por exemplo, indica que apenas as receitas de intermediações financeiras são necessárias para cobertura total das despesas operacionais. Isso implica afirmar que, quanto menor o índice, mais elevada é a produtividade.

No período observado, o Banco do Brasil apresentou índice de eficiência praticamente estável, com leve 
melhora em 2010. Os bancos privados não apresentaram um comportamento padrão no período observado, apresentando o Bradesco o pior comportamento do índice no período.

Esta análise demonstra a dependência das instituições financeiras por outras fontes de receitas, além da intermediação financeira, para cobrir o seu alto custo operacional com o objetivo de entrar na faixa do lucro.

Gráfico 4 - Índice de eficiência.

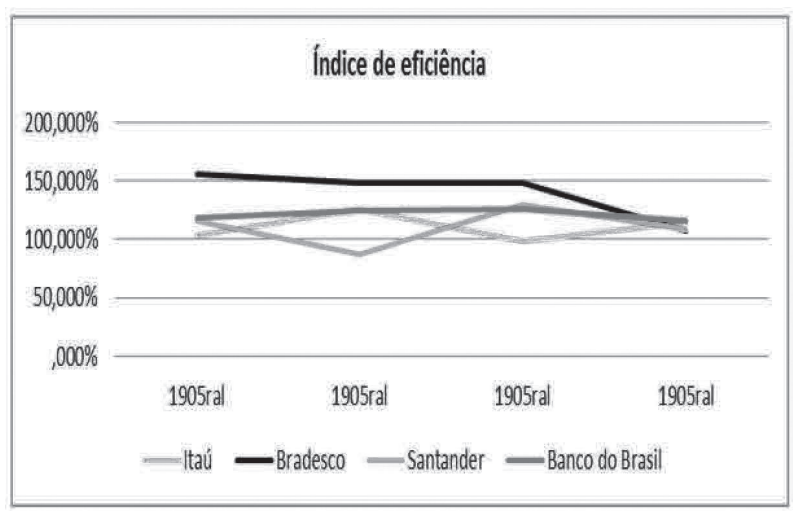

Fonte: elaborado pelo autor

O leverage, também conhecido como alavancagem, representa a relação dos ativos em relação ao patrimônio líquido da instituição. Por consequência, evidencia a participação do capital de terceiros para o financiamento dos ativos. Em função da natureza de sua atividade, as instituições financeiras têm uma tendência de possuir alto leverage, pois o principal negócio é a intermediação financeira, que nada mais é que captar capital de terceiros, em forma de depósitos, e repassar para seus clientes, na forma, principalmente, de operações de crédito.

A análise evidencia que o Banco do Brasil atuou de forma mais alavancada no período, provavelmente influenciado pelo incentivo governamental à concessão de crédito. O Banco Santander sofreu uma diminuição no nível de alavancagem devido ao aumento relativo em seu patrimônio líquido em proporção superior ao comportamento dos outros passivos, provavelmente influenciado pela aquisição do Banco Real no período. As instituições privadas também apresentaram alta no período de 2007 a 2008 , voltando a cair em 2009 e retomando o crescimento em 2010.
Gráfico 5 - Leverage (alavancagem).

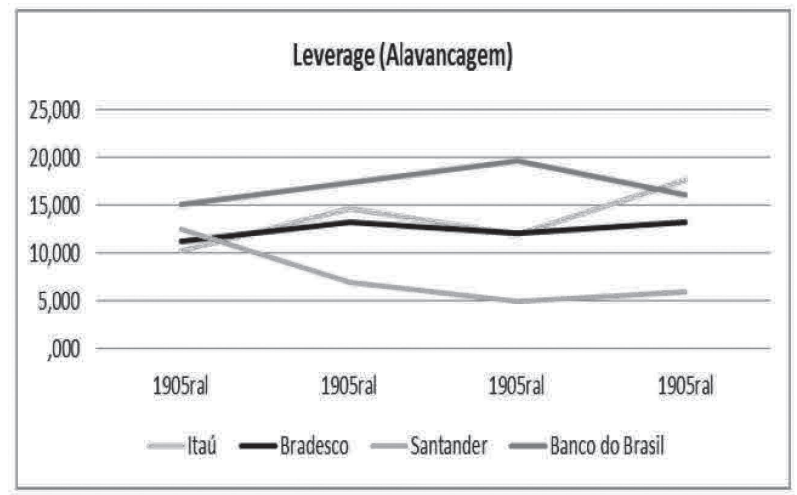

Fonte: elaborado pelo autor

O retorno sobre o patrimônio líquido representa o retorno dos acionistas. Com base no exposto no Gráfico 06, observa-se tendência de queda da rentabilidade do Banco do Brasil no biênio 2009/2010, pós-crise, influenciado pela postura adotada no período da crise financeira de 2008 relacionada à liberação de crédito para permitir que o mercado fosse menos atingido. O Itaú, que já vinha apresentando crescimento da rentabilidade em 2009, teve crescimento do retorno do patrimônio líquido mais acentuado que os dois outros bancos privados. Esse desempenho também foi influenciado pela aquisição do Unibanco. O Santander, apesar da tendência de crescimento, apresentou o nível mais baixo de retorno do patrimônio líquido, comparativamente aos outros bancos, influenciado principalmente pela aquisição do Banco Real no período 2008/2009.

Gráfico 6 - Retorno sobre o patrimônio líquido

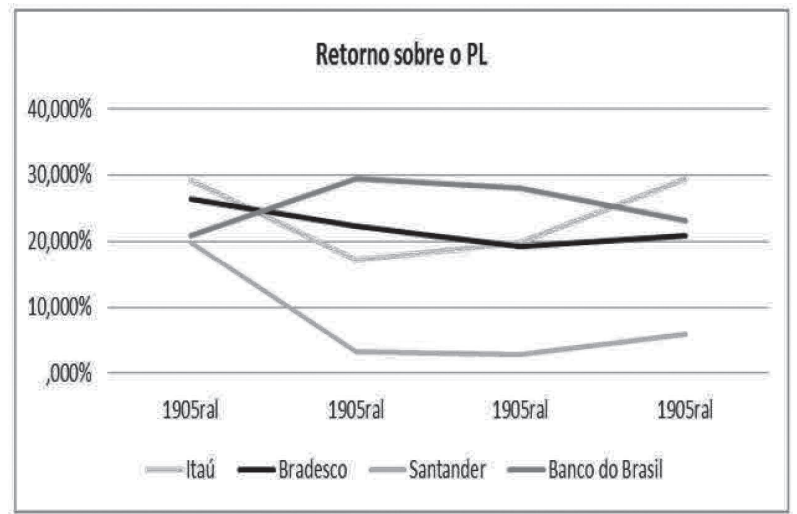

Fonte: elaborado pelo autor

O comportamento das operações de crédito em relação aos ativos evidencia estabilidade para o Banco do Brasil no período e crescimento acentuado das instituições privadas no biênio 2009/2010 após os níveis inferiores aos do BB em 2009. 
Os níveis de participação de operações de crédito do $\mathrm{BB}$ superiores aos dos bancos privados refletem as políticas governamentais de expansão do crédito no período. O Gráfico 07 evidencia que somente a partir de 2010 os bancos privados, mais avessos ao risco, iniciaram sua corrida em busca de aumento das operações de crédito, oferecendo menores patamares de taxas de juros aos seus clientes. Em resumo, 2010 apresenta-se como o período de retomada de mercado que os bancos privados haviam perdido em função de suas estratégias adotadas na crise de 2008.

Gráfico 7 - Participação das operações de crédito

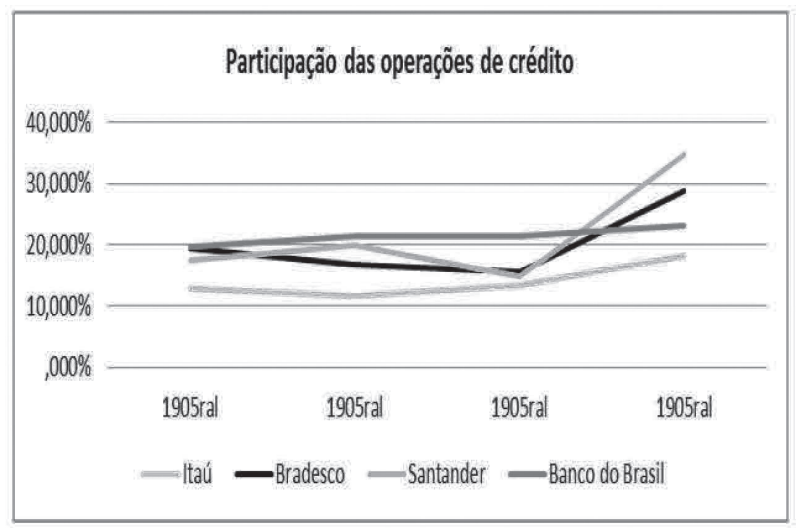

Fonte: elaborado pelo autor

\section{Considerações finais}

O presente trabalho teve como objetivo verificar o impacto da crise de 2008 na saúde econômico-financeira das instituições financeiras públicas e privadas que atuam na economia brasileira. Esse objetivo pôde ser alcançado por meio da análise dos demonstrativos contábeis (balanço patrimonial e demonstração de resultados) do Banco do Brasil S/A, do Itaú Unibanco S/A, do Bradesco S/A e do Santander Brasil S/A, referentes aos exercícios sociais de 2007, 2008, 2009 e 2010.

O questionamento proposto no início do trabalho de que "houve piora da saúde econômico-financeiras das instituições financeiras públicas, em relação às privadas, em função das medidas anticíclicas adotadas para conter a crise de 2008?" foi respondido ao se observar o comportamento dos indicadores econômico-financeiros calculados para as instituições analisadas.

A ação anticíclica do Banco do Brasil, por meio da ampliação do crédito em momentos de intensa prefe- rência pela liquidez, diante da contração de empréstimos por parte dos bancos privados, na busca de incentivar vários setores da economia e contribuir com menor intensidade da crise, foi acompanhada por um desempenho inferior aos dos bancos privados em relação aos indicadores de:

a) retorno sobre as operações de crédito: apresentou queda em 2010 superior à redução do indicador do Santander S/A, diante do crescimento do retorno dos outros dois bancos;

b) lucratividade: apesar de situar-se acima da lucratividade do Santander S/A, ficou abaixo do Itaú Unibanco S/A e do Bradesco S/A;

c) leverage:apesar do crescimento no biênio 2008/2009, apresentou queda diante do crescimento da alavancagem dos bancos privados objetos de análise;

d) retorno sobre o patrimônio líquido: apresentou tendência de queda diante da tendência de aumento do indicador dos bancos privados;

e) participação das operações de crédito: apresentou leve crescimento em 2010 diante do aumento acentuado do índice dos bancos privados.

Com relação aos comportamentos dos indicadores de custo médio de captação e índice de eficiência, não foi possível observar o efeito diferenciado da crise de 2008 no Banco do Brasil, em função das medidas anticíclicas, comparativamente aos bancos privados.

Não foi pretensão do presente trabalho esgotar o assunto sobre o efeito da crise de 2008 na situação das instituições financeiras que operam no Brasil por meio dos indicadores calculados. Os indicadores, pela sua natureza, não englobam todos os aspectos elucidativos para verificar a completa situação econômico-financeira das empresas. Há necessidade, inclusive, de que outras pesquisas sejam realizadas para verificar a eficácia das medidas adotadas pelo governo para minimizar os efeitos maléficos da crise e para constatar o impacto nas instituições financeiras. 


\section{Referências}

ASSAF NETO, Alexandre. Estrutura e análise de balanços: um enfoque econômico-financeiro. 10. ed. São Paulo: Atlas, 2012a.

ASSAF NETO Alexandre. Finanças corporativas e valor. 6. ed. São Paulo: Atlas, 2012b.

BADARÓ, Celeste Cristina Machado. A crise imobiliária estadunidense e seus reflexos. Disponível em: $<w w w$. pucminas.br/.../CNO_ ARQ_NOTIC20070925212952. pdf?.> Acesso em: 14 nov. 2011.

BANCO CENTRAL DO BRASIL. Relatório de economia bancária e crédito: 2009. Disponível em: <http://www. bcb.gov.br/?relecon09>. Acesso em: 14 nov.2011.

COMITÊ DE PRONUNCIAMENTOS CONTÁBEIS. Pronunciamento conceitual básico (R1): estrutura conceitual para elaboração e divulgação de relatório contábil-financeiro. Disponível em: <http://www.cpc.org. $\mathrm{br} /$ mostraOrientacao.php?id=14>. Acesso em: 25 mar. 2013.

FREITAS, Maria Cristina Penido de. Os efeitos da crise global no Brasil: aversão ao risco e preferência pela liquidez no mercado de crédito. Estud. av., São Paulo, v. 23, n. 66, 2009 . Available from <http://www. scielo.br/scielo.php?script $=$ sci_arttext $\&$ pid $=$ S010340142009000200011\&lng=en\&nrm=iso $>$. access on 15 May 2013. http://dx.doi.org/10.1590/S010340142009000200011. Disponível em:< http://www.scielo. br/pdf/ea/v23n66/a11v2366.pdf> Acesso em 24 mar. 2013.
LODI, Ana Luiz Guimarães. O papel dos bancos públicos do Brasil e da Índia no contexto da crise econômica mundial. 2010. Dissertação (Mestrado) - Programa de Pós-Graduação em Ciências Econômicas. Unicamp, São Paulo. 2010.

MARTINS, Gilberto de Andrade; THEÓPHILO, Carlos Renato. Metodologia da investigação científica para ciências sociais aplicadas. 2. ed. São Paulo: Atlas, 2009.

MESQUITA, Mário; TORÓS, Mario. Considerações sobre a atuação do Banco Central do Brasil na crise de 2008. Brasília, 2010. Disponível em: <http://www.bcb.gov.br/ pec/wpx/port/wps202.pdf>. Acesso em: 14 out. 2011.

PENMAN, Stephen H. Análise de demonstrações financeiras e security valuation. Rio de Janeiro: Campus, 2013.

PEREIRA, Luiz Carlos Bresser. A crise financeira de 2008. Revista de Economia Política, v. 29, n. 1, p. 133-149, jan./ mar. 2009.

SÍMBOLO da crise, quebra do Lehman Brothers completa umano. Folha on lineSão Paulo, 15 set. 2009. Disponívelem: $<$ http://www1.folha.uol.com.br/folha/dinheiro/ult91u 623945.shtml >. Acesso em: 03 out. 2012. 